\title{
CONVIVENDO COM A HOSPITALIZAÇÃO DO FILHO ADOLESCENTE ${ }^{1}$
}

\author{
Lindalva Carvalho Armond ${ }^{2}$ \\ Magali Roseira Boemer ${ }^{3}$
}

Armond LC, Boemer MR. Convivendo com a hospitalização do filho adolescente. Rev Latino-am Enfermagem 2004 novembrodezembro; 12(6):924-32.

Este estudo teve, como proposta, desvelar facetas da essência do significado de conviver com a internação de um filho adolescente, sob a óptica dos pais, por ser uma das minhas inquietações no cotidiano da prática docente assistencial. Fundamentando-me no referencial fenomenológico e à luz da analítica existencial de Martin Heidegger, mantive encontro com quinze pais de adolescentes que, no período de agosto a outubro de 2002, habitavam as Unidades de Internação do Hospital das Clínicas da Universidade Federal de Minas Gerais. A análise dos depoimentos obtidos nesses encontros, interligadas às minhas vivências e às leituras realizadas, possibilitaram a construção de quatro categorias temáticas que sinalizam a essência desse conviver: o impacto da doença na família, os sentimentos vividos pela família e a adaptação no mundo hospitalar; a religiosidade e a presença dos amigos no enfrentamento da hospitalização; as transformações do filho. Ao refletir sobre a experiência dos pais, contemplo a necessidade de pensar o adolescente e sua família como um ser-aí, sendo-no-mundo e sendo-no-mundo-com-os-outros.

DESCRITORES: família; adolescente; hospitalização

\section{LIVING WITH A HOSPITALIZED ADOLESCENT}

This study aimed to understand the experience of parents living with a hospitalized adolescent. Fifteen parents of hospitalized adolescents were interviewed from August to October of 2002. Data were analyzed through Martin Heidegger's phenomenological approach. Four themes were identified: the impact of the illness on the family, the feelings of the family members and the adaptation to the hospital world, religiousness and the presence of friends in the process of coping with hospitalization; changes in the adolescent. The results showed the importance of seeing the adolescent and his/her family as a being there, being-in-the-world and being-in-the-world-with-others.

DESCRIPTORS: family; adolescent; hospitalization

\section{CONVIVIENDO CON LA HOSPITALIZACIÓN DE HIJO ADOLESCENTE}

Este estudio tuvo como propuesta desvelar facetas de la esencia del significado de convivir con la internación de un hijo adolescente bajo la óptica de los padres, considerando ser ésta una de mis inquietudes en el cotidiano de mi práctica docente-asistencial. Con fundamento en el referencial fenomenológico y a la luz de la analítica existencial de Martín Heidegger, entrevisté a 15 padres de adolescentes que en el período de agosto a octubre de 2002 habitaban la Unidad de Internación del Hospital de Clínicas de la Universidad Federal de Minas Gerais. El análisis de las declaraciones obtenidas en esos encuentros, interligado a mis vivencias y las lecturas realizadas, posibilitó la construcción de categorías temáticas, que indican la esencia de ese convivir: el impacto de la enfermedad en la familia, los sentimientos vividos por la familia y la adaptación al mundo hospitalario, la religiosidad y la presencia de amigos en el proceso de enfrentamiento de la hospitalización, las transformaciones del hijo. Al reflexionar sobre la experiencia de los padres, contemplo la necesidad de considerar al adolescente y a su familia como un ser ahí, siendo en el mundo y siendo en el mundo con los otros.

DESCRIPTORES: familia; adolescente; hospitalización

\footnotetext{
${ }^{1}$ Trabalho extraído da tese de doutorado apresentada à Escola de Enfermagem de Ribeirão Preto, da Universidade de São Paulo; ${ }^{2}$ Doutoranda, Professor Assistente da Escola de Enfermagem da Universidade Federal de Minas Gerais, e-mail: lindalva_armond@uol.com.br; ${ }^{3}$ Orientador, Professor Livre-Docente Aposentado da Escola de Enfermagem de Ribeirão Preto, da Universidade de São Paulo, Centro Colaborador da OMS para o desenvolvimento da pesquisa em enfermagem, Pesquisador 1 A - CNPq, e-mail: boemer@eerp.usp.br
} 
INTRODUÇÃO

$\boldsymbol{A}$ aproximação com o tema Adolescência e sua inclusão em meu mundo-vida teve início nos momentos em que, no desenvolvimento do ensino clínico da Disciplina Enfermagem Pediátrica do Curso de Graduação em Enfermagem da Universidade Federal de Minas GeraisEEUFMG, pude vivenciar o contexto da hospitalização para 0 adolescente.

Chamava-me a atenção, na Unidade Pediátrica, a insegurança dos profissionais de saúde ao cuidar do adolescente, a assistência pautada quase que exclusivamente no desempenho de tarefas e o sofrimento da pessoa que, com a doença, via-se separada de seu mundo e dos seus vínculos afetivos. Naquele momento, meus questionamentos transformaram-se em objeto de estudo e originaram minha dissertação de mestrado: "Buscando compreender o fenômeno da hospitalização para o adolescente"(1).

Desvelar o significado, para o adolescente, de estar hospitalizado permitiu-me compreendê-lo, vê-lo em si mesmo, aproximar-me do seu mundo-vida e ter a compreensão de que é necessário ver a pessoa em sua totalidade, imaginar-se no lugar do outro para vê-lo como ele é, com seus medos, suas tristezas e suas expectativas.

Entretanto, compreender o significado da hospitalização para o adolescente possibilitou-me iluminar uma faceta desse fenômeno, pois permanecia ainda oculto o sentir dos pais ou de quem, simbolicamente, representava a vinculação familiar ao vivenciar a doença e a internação de um filho adolescente. Chamava-me a atenção a presença dos pais junto ao seu filho doente, vivenciando sua dor, acompanhando o processo terapêutico e a realidade do mundo extra-hospitalar, que exigia sua presença em casa, nos locais de trabalho; o convívio com outros membros da família e sua participação em compromissos familiares, profissionais e sociais.

Vários estudos com crianças, adolescentes e suas famílias têm mostrado que a doença e a hospitalização de um dos seus membros afeta, também, todos os demais membros da família. Os autores afirmam que a pessoa e sua doença não podem ser mais os únicos focos da atenção da enfermeira. A família também deve ser vista como foco dessa atenção, para a humanização da assistência de enfermagem ${ }^{(2-5)}$.

Assim, minhas inquietações anteriores se reconfiguraram sob outro questionamento: Que significado os pais atribuem a seu conviver com tudo isso, levando ainda em consideração ser o filho um adolescente? Como seria habitar o mundo hospitalar com o filho adolescente?

A literatura pesquisada revelou que a família é considerada a instituição mais sólida desde o princípio da era cristã e tem sido objeto de estudos nos últimos anos no Brasil e em todo o mundo. Ela vem passando por transformações constantes, mudando sua estrutura, sua organização, seus valores e seus papéis, influenciada pelas transformações socioeconômico-culturais de nossa sociedade. Assim, histórica e sociologicamente, não existe um modelo de organização familiar que possa ser considerado único ${ }^{(6-7)}$.

A palavra adolescência origina-se do verbo latino "adolescere", que significa a idade que cresce e, cronologicamente, encontra-se, conforme a Organização Mundial de Saúde-OMS, compreendida entre 10 e 19 anos. Entretanto, ela não se mede pela idade cronológica ou pelo peso e estatura individual, mas, sim, pelas interrogações que angustiam o jovem, pelos seus desejos e temores e pela busca e encontro da identidade própria, individualizada. Durante muito tempo não houve preocupação em estudar essa etapa da vida, mas, hoje, ela é considerada a mais nova fronteira da Pediatria ${ }^{(8)}$.

As primeiras menções à Adolescência vêm da Antigüidade e, na Idade Média, poucas são as referências sobre ela. $O$ de que se tem conhecimento é que, durante esse período, existia uma ambigüidade entre a infância e a adolescência e as crianças eram forçadas a viver no mundo dos adultos, tornando-se "miniaturas" deles. Entretanto, a adolescência evoluiu de fato no século XX, após a Revolução Industrial, sendo seu grande marco a transformação social ocorrida depois da II Grande Guerra e o nascimento da cultura jovem, quando a oposição ao mundo do adulto tornou-se um dos objetivos básicos do mundo do jovem ${ }^{(6)}$.

As primeiras propostas de atendimento à saúde do adolescente no Brasil surgiram em São Paulo, na rede ambulatorial, tendo como foco principal a promoção da saúde e a prevenção de agravos. Paralelamente, no Rio de Janeiro, o atendimento deu-se a partir dos adolescentes internados, tendo como enfoque a abordagem curativa e a reabilitação ${ }^{(8)}$.

Por meio da Constituição Federal, o Brasil garante um dos mais avançados sistemas de direitos da criança e do adolescente. $\mathrm{O}$ art. 227 considera ser dever da família, 
da sociedade e do estado, protegê-los de toda as formas de negligência, discriminação, violência, crueldade e opressão $^{(9)}$.

Em 1989, foi aprovado pela Divisão Nacional de Saúde Materno Infantil-DISAMI, do Ministério da Saúde, o Programa Saúde do Adolescente-PROSAD, que define os objetivos, as diretrizes e as estratégias de atendimento a essa clientela ${ }^{(10)}$. Em outubro de 1990, passou a vigorar o Estatuto da Criança e do Adolescente-ECA, que garante, em seu artigo $12^{\circ}$, que as instituições de atendimento à saúde devem proporcionar condições para a permanência, em tempo integral, de um dos pais ou responsável, no caso de internação da criança e do adolescente ${ }^{(11)}$.

A preocupação da enfermagem com as necessidades dos jovens levou a Associação Brasileira de Enfermagem-ABEn, por meio do "Projeto Acolher", em parceria com o Ministério da Saúde, a instituir, no ano 2000, um desafio aos seus profissionais, para que implementassem e divulgassem suas práticas e reflexões sobre a saúde do adolescente ${ }^{(12)}$.

Assim, estudos realizados comprovam que: "os enfermeiros precisam buscar aprofundar conhecimentos por meio da pesquisa sobre essa etapa da vida do ser humano, dentro de um contexto sociopolítico e cultural. Dessa forma, poderão planejar uma assistência de qualidade, voltada para as necessidades dessa população", ${ }^{\text {(13) }}$.

$\mathrm{Na}$ adolescência, é necessário que os pais se aproximem do mundo dos filhos, descobrindo, junto com eles, na experiência da vida, as nuanças que fazem do adolescer um processo de crescimento e de encontro consigo mesmo. Esse período é também difícil para os pais. Eles percebem o filho confuso, sentem-se apreensivos quanto a sua luta em busca da maturidade emocional e temem falhar como pais. Acresce-se a isso o fato de que o adolescente vive, além dos agravos físicos e biológicos, aqueles decorrentes da busca de estabilização de sua personalidade, ou seja, do seu EU.

Portanto, a doença e a hospitalização na adolescência constituem uma crise importante na vida dos adolescentes e, como foi dito anteriormente, afetam cada membro da família nuclear e, em graus variados, os outros membros.

Habitando o mundo hospitalar, observei que a internação rompe a rotina pré-estabelecida do adolescente e da família, ocasionando, muitas vezes, um verdadeiro caos. Na medida em que o sofrimento físico aumenta, a angústia se exacerba, o adolescente muda sua postura e passa a exigir a presença constante da mãe ou da figura materna, utilizando-se, muitas vezes, do choro, de ameaças e de chantagens como forma de garantir essa presença $a^{(1)}$.

Tal constatação trouxe-me inquietações do que significaria para os pais conviver com a internação do filho adolescente.

\section{METODOLOGIA}

Para compreender o vivenciar da mãe ou do pai do adolescente doente, no que tange à experiência da internação de seu filho, foi realizado este estudo que se fundamentou na fenomenologia, dada a natureza desse objeto de investigação: "se é com seres humanos que vamos lidar, então devemos buscar a essência e a natureza constitutiva desses seres humanos, que se colocam diante de nós"(14).

A fenomenologia possibilita aproximar-se da pessoa, de seu mundo vivido, percebendo-a com seus sentimentos, frustrações e inferências, compreendendo os significados por ela atribuídos à situação que está sendo pesquisada. Para compreender o homem, é preciso entender que o ser-aí ou DASEIN, é o ser-no-mundo, é ser-no-mundo-com-os-outros, e isso inclui a característica fundamental de como me relaciono, atuo, sinto, penso e vivo com meus semelhantes, o ser humano. Não sendo a existência isolada, a experiência da existência se dá numa relação interpessoal e intersubjetiva. O fenômeno não se desvela totalmente porque sempre haverá um sujeito para o qual ele se mostra em diferentes perfis. No processo de comunicação, pesquisador e sujeito estão juntos no mundo-vida, co-participando de experiências vividas, estabelecendo a intersubjetividade de estar-com ou seja, em co-existência ${ }^{(15)}$.

Para chegar à compreensão do fenômeno: "pais convivendo com a hospitalização de seus filhos adolescentes", recorri à entrevista como forma de obter os depoimentos, porque "o ser-com é partilhado no discurso; é através dele que a pre-sença se pronuncia"(15).

O estudo foi realizado no Hospital das Clínicas da Universidade Federal de Minas Gerais, HC/UFMG, após aprovação do Comitê de Ética e Pesquisa-COEP, da Diretoria de Ensino, Pesquisa e Extensão-DEPE e da Divisão Técnica de Enfermagem-DTE, e a dimensão 
bioética foi assegurada com o respaldo na Resolução 196/ 96 , que regulamenta a pesquisa com seres humanos ${ }^{(16)}$.

Os sujeitos da pesquisa constituíram-se de quinze pais de adolescentes internados no período de agosto a outubro de 2002 e que permaneciam no hospital acompanhando seus filhos. Dessa forma, por meio da questão norteadora: "Fale para mim como está sendo conviver com a internação de seu filho adolescente?", busquei compreender a experiência dos pais com a hospitalização do seu filho adolescente. As entrevistas foram gravadas após consentimento dos pais e a obtenção dos discursos se encerrou a partir do momento em que os depoimentos colhidos tornaram-se repetitivos, permitindo o desocultamento de parte do fenômeno e considerando-se a proposta do estudo. Os depoimentos foram transcritos, permitindo a análise e a reflexão dos discursos dos pais*.

\section{DESVELANDO O SENTIR DOS PAIS DOS ADOLESCENTES}

Na trajetória da análise, percorrendo os discursos, ouvindo atentivamente as gravações e fazendo a transcrição de cada uma delas, rememorei, além das falas, os silêncios, os gestos, a entonação da voz, as reticências, a maneira de ser de cada uma das pessoas entrevistadas.

Os temas encontrados possibilitaram-me adentrar no vivido dos pais e desvelar seu conviver com a hospitalização do filho adolescente. Quatro grandes categorias temáticas foram construídas, as quais sinalizam a essência desse conviver.

A doença tornando-se "Presença" no cotidiano dos pais

Os discursos dos pais levaram-me a apreender que a experiência com a doença e a hospitalização de um filho é tão impactante para a família que a sua primeira reação, quando thes perguntei sobre o significado da hospitalização de seu filho, foi responder sofridamente, com poucas palavras**: é muito difícil pro pai e pra mãe ficar num hospital com o filho ( $E$ 4), é como se eu estivesse vivendo um pesadelo (E 3).

O aparecimento brusco dos sintomas e a necessidade de internação significam uma experiência marcante no processo da doença, e os pais explicitam que ele adoeceu assim de repente, teve que internar, aí eu fiquei desesperada (E5). Surpresos, compreendem que não podem permanecer inertes e assumem postura de enfretamento da situação, tomando novas decisões, incorporando o sentido da doença em suas vidas. Assim afirmam: ....ultimamente tô tendo que ficar por conta, não estou tendo condições psicológicas de conciliar hospital, casa e serviço... (E 1), ...eu larguei até o meu serviço, eu tô desempregada (E 7).

Os pais sentem que perderam o controle e a liberdade de suas vidas, criando novas possibilidades de ser no mundo, mundo do qual a doença e a internação do filho agora fazem parte. Prá nós está sendo tipo de uma crise porque a gente quase não conversa, ela chega, ela vai, ela vem e eu vou prá lá. A nossa vida está uma rotina ( $E$ 4).

No enfrentamento da internação, a mãe colocase no lugar do filho e é absorvida de tal maneira que se sente junto com ele, também, a se considerar internada. Assim, vivendo as experiências e expectativas com o filho, os pais se despojam de seu "Eu", para, junto com o filho, tornar-se "Nós"; são pre-sença e co-participam de suas vivências e se exprimem: Já tem um mês que estou aqui e nós vamos receber alta, acho que essa semana...(E 15). Assim, no envolvimento com o filho, o encontro se faz presente. Esse encontro com o outro, segundo Heidegger, é determinação da pre-sença, pois "o mundo da pre-sença é um mundo compartilhado. O ser-em é ser-com os outros. O ser-emsi intramundano desses outros é co-presença"(15).

Entretanto, com a internação, o adolescente percebe profunda alteração no seu mundo-vida, afetando o seu ser-si-mesmo e o seu ser-com-os-outros na família e com os amigos. Os pais afirmaram: Prá ele foi um baque muito grande (E 1). Ele sente perdido, tá perdido ele mesmo (E 2).

O mundo do hospital vai se mostrando aos adolescentes e aos seus pais. É um descortinar lento, sofrido e implica um desafio para eles. O ser adolescente sofre ao habitar esse novo mundo e manifesta seus sentimentos aos pais, nem sempre apenas pela linguagem verbal, mas também pela gestual, corporal e silenciosa: Ela tá com soro, aquela cara dela ali é porque ela tava solta, ela tava livre e hoje já colocou essa coisa.(E 7) .... ele fica assim muito triste, ele se sente muito só (E 3).

Os discursos revelam como é difícil para os adolescentes se verem privados do seu mundo anterior,

\footnotetext{
* Os depoimentos dos pais encontram-se com a autora à disposição dos leitores

** Refere-se à ordem cronológica de obtenção dos depoimentos
} 
com o qual estão familiarizados. Nesse mundo, Heidegger faz referência ao ser-aí (Dasein) e o define como as várias maneiras que o existir humano tem possibilidades de viver consigo mesmo e com os outros. "Ser-no-mundo é sempre algo que eu partilho com os outros. O mundo do ser-aí é um mundo-com (Mitwelt). Ser-em é ser-com-outros"(17).

Quando, na facticidade de estarem doentes, os jovens se afastam do convívio escolar, há uma desestruturação ainda maior do seu mundo-vida. O mundo do hospital é revelado como um mundo transitório, não absorvido na existência desse adolescente e torna-se clara a separação que faz entre os dois mundos: o seu e o do hospital. A expressão "aqui" torna-se reveladora e mostra esse distanciamento, essa dicotomia: Mãe, leva os cadernos embora, quando eu voltar eu estudo. Aqui, eu não quero saber de nada não (E 2).

O estudo também revelou que a ocorrência da doença e da hospitalização de um filho afeta cada membro da família nuclear e, em diferentes graus, todas as outras pessoas. Os pais vivem os mais conflitantes sentimentos: preocupação e sofrimento em seu sendo-com-o-filhodoente e com-os-outros-filhos, cuidando do filho que está hospitalizado e delegando a outras pessoas o cuidar dos filhos que estão em casa. Nesse contexto, os pais são presenças constantes com seu filho doente e se percebem como presenças ausentes dos seus outros filhos. Vivem sentimentos de culpa, impotência, ansiedade e medo ...a gente tem que ficar pra lá e pra cá... só o pai e a mãe pode ficar... (E 5). Nós também temos dois filhos dentro de casa, adolescentes, preocupa demais"(E 1). Ah! é difícil ter os outros em casa e ela aqui (E 6).

O mundo hospitalar absorve os pais de tal forma que as situações deixadas para trás, pela internação, são intensificadas, pois o "olhar" dos pais volta-se para o filho doente, e outras pessoas são chamadas para interagir na família: ...agora, tem minha irmã cuidando dos outros porque eu falei que a $A$. está precisando de mim (E 7).

Essas situações vividas acabam por trazer novos conflitos para os pais porque as manifestações dos irmãos, frente à doença e à hospitalização de um irmão ou irmã, também revelam sentimentos conflitantes ...eles ficam lá tristes, tanto o pai, como os avós, os tios, ...querendo saber o que está se passando com ele e perde a alegria (E 3).

Para Heidegger, é o relacionar-se-com-os-outros de maneira envolvente e significante que delineia a característica de ser-com-o-outro. Há duas possibilidade de solicitude: saltar sobre o outro e dominá-lo, manipulálo, fazendo tudo por ele, e saltar diante do outro, possibilitando que ele assuma seus atos e caminhos, que ele seja ele mesmo. Esse último refere-se ao autêntico "cuidar"(15).

Às vezes é preciso mobilizar toda a família para que o cuidar se presentifique: Ah, é difícil, eu não moro aqui... minhas meninas ficam com minha mãe. Tem quase três anos de tratamento da $R$., elas ficam mais com a mamãe (E 11).

\section{Descortinando um novo mundo}

Penetrar no mundo dos sentimentos dos pais foi uma das experiências mais marcantes, enquanto profissional de saúde, mulher e mãe. Escutar, empaticamente, uma mãe dizer o que muitas vezes, pensamos, de imaginar a doença em outras famílias, mas não em nossos filhos, remeteu-me à concretude de que só vivemos por meio de nossas experiências; o que é vivido pelos outros nos aproxima, torna-nos parceiros e, por isso, para compreendermos a experiência do outro, é necessário estarmos-com-ele, junto-dele para, atravésdele, descobrirmos o ser que se oculta. Dessa forma, os depoimentos revelam a experiência singular dos pais de estar-com-o-filho doente: NÓS $^{\star}$ ficamos um mês e uma semana internadas (E 7). O difícil é ver ela doente... Então, a gente vai superando, vai levando até poder dar alta e A GENTE poder ir embora (E 13).

As manifestações dos filhos são igualmente angustiantes para os pais que, conscientes de que são o seu apoio, lutam para não sucumbir, para não fraquejar. $\mathrm{E}$, assim, apesar de todo sofrimento, permanecem fortes junto dos filhos. É uma coisa assim, é muito difícil, a gente tenta, eu tenho que ser forte, por ele, por mim também... a hora que eu quero chorar, eu entro para o banheiro, não a título de reclamar, eu não choro para reclamar... É mais a título de lavar a alma, sabe? (E 10). ...a gente agüenta, quem é mãe tem que agüentar esses problemas... ser mãe a gente sofre demais, eu passei uma barra... (E 14).

No início, a internação apresenta-se permeada por intensa dor existencial, desestruturando e desestabilizando o ser do adolescente e dos familiares. As lágrimas e a revolta dominam a cena, o vivido e a linguagem de cada sujeito: ...no início ele ficou muito revoltado, ficar sem andar, sem ir prá escola, tem quase um mês que a gente tá aqui... (E 5). É difícil porque a $R$. não aceita o tratamento (E 11).

* Grifos das autoras 
Com o passar do tempo, o sofrimento dos pais permanece, mas é amenizado vendo o filho ser bem tratado, aceitando melhor o tratamento, tendo maior conhecimento da doença, familiarizando-se com o hospital. Começam a interagir entre si, com os profissionais do serviço, com os outros pacientes e seus familiares. Os pais sentem necessidade de compreender a doença, de adquirir conhecimentos sobre o tratamento e percebem que ainda são capazes de cuidar dos filhos. Eles afirmam que é importante a interação com os profissionais de saúde na trajetória de estarem hospitalizados. ...os próprios médicos explicam pra gente...ele está a par de tudo... os médicos, o Dr. X, a Y., a Drª Z. já conversaram direto e com ele. Eles me dão acesso aos exames dele. Então, isso aí é muito importante, eu estar sabendo (E 10).

Ao acompanhar o filho durante sua internação hospitalar, os pais contribuem para atenuar as adversidades desse momento vivenciado pelo seu filho, auxiliando-o para uma melhor aceitação dos procedimentos aos quais será submetido, identificando, mais precocemente, suas necessidades: Porque menina, numa hora dessa, precisa da mãe (E 7) ...não é por ele ser adolescente que eu ia deixar de acompanhar ele (E 8).

Os procedimentos hospitalares, o repouso imposto no leito, o medo de uma imagem corporal alterada, a falta de privacidade, o uso de determinados equipamentos modificam o sentimento de controle e poder, justamente no momento em que os adolescentes estão lutando para buscar uma identidade própria, tornando-se, dessa forma, um dos grupos mais vulneráveis ao estresse da doença e da hospitalização. A participação de outras pessoas interagindo no hospital ameniza os sentimentos de perda e o distanciamento dos outros familiares e amigos: ...o pessoal mais antigo estava falando que, antes, não ficava acompanhante e, graças a Deus, ele está tendo isso agora porque, se fosse numa outra época, eu não conseguiria ficar perto dele (E 10).

Os pais se ressentem de não haver um espaço específico para os jovens na Unidade de Internação e deixam claro como essa situação influencia seu filho: ...quando ela internou, ela conviveu com crianças, com bebês...(E 15). ...talvez ela não esteja gostando porque é lugar de criança... (E 14) ...no momento que ele internou tinha dois menininhos ao lado dele, e as duas mães... (E 6). Eles destacam também a importância do acesso a atividades de lazer para que o filho possa extravasar seus medos e ansiedades, abrindo possibilidades para conviver com a angústia: ...tá tendo a biblioteca aqui, ela ficou super alegre... podia pegar revista para ler... descontraiu ela demais, passa mais rápido o tempo (E 12).

Os pais relatam também que é difícil para o filho aceitar e conviver com as regras hospitalares, com as limitações por elas impostas e com o cerceamento de ir e vir: ...eu quero deixar bem claro é o negócio das visitas. Porque eles deixam duas visitas só, ...veio quatro hoje visitar ela, duas só puderem entrar. As outras duas ficaram lá em baixo, chorando, querendo ver ela, não conseguiu entrar... (E 12).

Apesar das restrições, mas tendo consciência de que o homem, para conviver em sociedade, necessita ter normas, seguir regras e desenvolver padrões de comportamento, os pais se conformam e buscam amenizar junto aos filhos o impacto que essas lhes causam. A fala de uma mãe retrata esse vivido: Tá bom, tirando as leis* que a gente tem que respeitar, infelizmente ou felizmente porque a gente nunca sabe, porque, se tem uma lei, é porque precisa, né? (E 10).

\section{Sendo-com-o-outro na dor}

A religião desempenha um papel fundamental na formação moral, ética e cultural do ser humano, proporcionando-lhe a compreensão da realidade da vida e de seus objetivos essenciais. É significativa a confiança que os pais depositam em Deus e o conforto espiritual que este acolhimento Ihes proporciona, dando-lhes forças para superar a situação que estão vivendo. A esperança foi a tônica de todos os discursos, conforme explicitado: ...eu fico aí agora, até levantar de vez, se Deus quiser nós vamos sair dessa (E 2) ...É só Deus que pode mover as pernas da pessoa, mover os dedos, mover os nervos, mover tudo isto (E 4).

A doença revela, para o ser-doente, a possibilidade da morte, ou seja, sua finitude. O homem é um ser de possibilidades, e a morte é a possibilidade maior enquanto ser-no-mundo. Apesar de nenhum dos entrevistados ter explicitado, em seus depoimentos, a possibilidade da morte de seu filho adolescente, parece inegável a presença dela, ainda que nas entrelinhas: Eles trouxeram ele prá cá e disseram que ele estava bem ruim... graças a Deus, que eles deram a chance dele tratar (E 5). Graças a Deus $A$. já venceu a batalha e nós já vamos embora amanhã (E 7).

Diversos estudos com pacientes em estado terminal e com portadores de doenças crônicas revelaram

* Grifo das autoras 
aos seus autores a experiência singular desses pacientes perante sua finitude, os sentimentos de suas existências como seres-no-mundo e suas relações com o mundo das coisas e com outras pessoas. Neles, foi desvelado que a morte faz emergir a sensação de impotência quanto a nossa finitude, remetendo aos sonhos não realizados e ao sentido da existência ${ }^{(2-4,18)}$. Toda uma linguagem não verbal desnuda o quanto o adolescente é afetado pela morte de alguém: No sábado faleceu um rapaz na mesma enfermaria que L. tá, com o mesmo problema. Então, até hoje ele está esmorecido, tem horas que ele fica assim quietinho, caladinho, não fala nada comigo. Eu acho que ele deve ter ficado com trauma daquilo... (E 9).

Quando um filho é internado, toda a família e as pessoas com quem mantém vínculo afetivo são afetadas. Nessas circunstâncias, elas estabelecem entre si algumas bases necessárias para o enfrentamento da doença e da internação: E minha mãe me ajuda, meu pai vem e me ajuda (E 1). A minha salvação é a tia dela que veio pra casa, então a gente troca... (E 6).

A ausência de um companheiro significou mais um momento de dor na experiência da internação: $O$ pai dela costuma vir com ela, mas agora ele não pode vir (E 14); porém, a presença dos amigos vai proporcionar ao ser doente 0 elo que assegura seu vínculo com o "seu mundo": Tem dois amigos que eles são como irmãos, eles automaticamente têm me dado muita força, sabe?... está sendo muito importante a presença dos amigos (E 10).

Além da presença dos familiares e amigos, ter o apoio da escola tranqüiliza os pais que têm, no momento, a preocupação maior voltada para o tratamento e para a cura da doença, porém não se esquecem da importância da escola na vida do filho. Mas o pessoal da escola me ajuda com a cesta básica, eles me ajudam... (E 7). Os professores ligam, estão indo dar sangue... Sabe, isso tem ajudado ele muito. A solidariedade nesta hora é muito importante (E 10).

A adolescência é o período em que o jovem se abre para a vida e, nessa fase do existir, podemos evidenciar a busca por um relacionamento a dois. Para um adolescente internado, foi fundamental a presença da namorada, e sua mãe relata: ...ele tem uma namorada... $A$ princípio, ela não sabia. Ela chorou muito... está aí firme, dando muita força, fazendo ele comer (E 10).

No envolvimento do ser com o outro ser, novas relações se concretizam, e os pais "internados" também se unem e passam a compartilhar dos mesmos sentimentos. ...eu estou aprendendo muita coisa aqui dentro .A gente fica assim sensibilizada com o problema dos outros... eu estou fazendo novas amizades, com gente que está passando a mesma coisa, que já passou a mesma coisa que eu estou passando, que está me dando força... (E 10).

Filho- um ser revelador e em transformação

O tema deste estudo possibilitou que os pais revelassem os momentos de sofrimento que estavam passando no hospital. Falar, então, sobre o modo de ser dos filhos foi como uma pausa nesse sofrimento. $\mathrm{O}$ tom de voz alterou, a expressão mudou, e a tensão percebida até então foi amenizada: $A$. é uma menina muito educada, muito calma. Apesar de tudo que ela já passou, ela é uma menina muito calma... Tem 11 anos e cuida dela direitinho (E 7). Ele corria pra todo lado, era um menino excelente pra mexer, tudo nele era perfeito (E 4).

Os discursos dos pais revelam, ainda, a responsabilidade dos filhos em relação aos estudo e à preocupação que têm de não se prejudicarem com a situação da doença. Ele está de greve... a gente procurou o hospital nesse momento, porque a escola está de greve... ele pediu, assim, eu não perco aula (E 8).

Com o passar dos dias, por meio da interação com os profissionais de saúde e conhecendo mais sobre a doença e o tratamento, vai havendo um sentimento de resignação e ambos, pais e filhos, sentem-se mais adaptados à Unidade de Internação: ...o acompanhamento é total, foi muito importante o médico mandar o psicólogo pra ela ( $E$ 15), ...ele, felizmente, não tem nada a queixar... (E 9).

Somente uma adolescente não alterou sua conduta e recusou submeter-se a parte do tratamento: $\dot{E}$ difícil porque a $R$. não aceita o tratamento.. ela já está grande também, já entende as coisas, ela ia passar por um transplante em março, mas ela não passou porque ela não quis (E 11).

A adolescência é o momento em que as modificações puberais levam o jovem a perceber que está se transformando. Ele vê sua imagem corporal, construída desde a infância, sendo reformulada. Seu relacionamento consigo mesmo e com os outros vai assumindo novas configurações. A hospitalização dificulta ainda mais essa fase: Tá adolescendo, ele começando agora, com 13 anos, ele dentro do hospital, pra ele foi um baque muito grande... (E 1), ela já está com 11 anos e tem três anos que ela tem esse problema, ...ela já está mais pra adolescente, então eu acho mais difícil... (E 6).

A imagem corporal, em intensa modificação, deixa o jovem bastante inseguro quanto ao seu corpo. A realização de certos procedimentos, em sua maioria nas 
enfermarias, exacerba esses sentimentos: É que aqui não tem uma privacidade né?. Então, prá trocar de roupa fica difícil, pra ir ao banheiro também, porque fica aquele entra e sai de pessoas no banheiro, ela está mudando de corpo, fica difícil (E 12). Ele ficou com vergonha, com esse negócio de ficar passando sonda, ele ficou muito acanhado (silêncio)... ele já tá ficando rapazinho, vai fazer 12 anos. (E 5). A moça queria por ela na comadre e ela falou: não vou mesmo, não coloco mesmo, e falou: mãe, não vou fazer xixi...ela tem quinze anos, ela não vai querer fazer, tem mais gente no quarto (E 12).

Apesar de a adolescência ser uma fase universal, sua característica mais marcante é que ela é individual. Assim, acompanhando o filho no processo de adolescer, alguns pais se manifestam vendo o filho às vezes como criança ou às vezes como um adulto: Eu, como mãe mesmo, não é por ele ser adolescente, que eu ia deixar de acompanhar ele... é adolescente, mas, no fundo, no fundo, ainda é uma criança também (E 8), Ele tem tido muita força. Eu não falo uma criança mais, porque eu não consigo vê-lo como uma criança mais, porque a adolescência já aflorou nele, né, fisicamente (E 10).

Eles acrescentam ainda que toda essa situação de internação acarreta em seus filhos sentimentos de mal estar, constrangimento e de vergonha. O significado que cada adolescente atribui a sua doença varia aos olhos dos pais: Eu tenho percebido alteração de humor, principalmente quando ele quer uma coisa que ele não está podendo ter (E 10). Ela já está adolescente, quatorze anos. Ela já sabe bem o que quer e o que não quer (E 11).

As facetas afloradas nos discursos dos pais foram por mim apreendidas e desvelaram o fenômeno do que é conviver com a internação do filho adolescente. $O$ desvelamento de um fenômeno é perspectival. Novos desvelamentos podem e devem ser feitos a partir de outras inquietações, para que, compreendendo esse fenômeno, possamos vislumbrar novas perspectivas na assistência ao ser adolescente e sua família hospitalizados.

\section{REFERÊNCIAS BIBLIOGRÁFICAS}

1. Armond LC. Buscando compreender o fenômeno da hospitalização para o adolescente. [dissertação]. Belo Horizonte (MG): Escola de Enfermagem/UFMG; 1996.

2. Valle ERM. Ser-no-mundo-com-o-filho portador de câncer: hermenêutica de discurso dos pais. [tese]. São Paulo (SP): Instituto de Psicologia/USP; 1988.

3. Oliveira AGC. Convivendo com a doença crônica da criança: a experiência da família. [tese]. São Paulo (SP): Escola de Enfermagem/USP; 1994.

4. Angelo M. Com a família em tempos difíceis: uma perspectiva de enfermagem. [tese]. São Paulo (SP): Escola de Enfermagem/USP; 1997.
PERSPECTIVAS A PARTIR DO DESVELADO

Penetrar no mundo vivido, observando os pais, no momento da entrevista, lendo atentivamente seus depoimentos, possibilitou-me vislumbrar o impacto da doença para a família e afirmar que internar um filho, seja criança ou adolescente, é um grande sofrimento para os pais.

Compreender como a família convive com a hospitalização abre novas perspectivas no meu assistir em pediatria: é necessário resgatar o ser humano que existe em cada ser-doente para repensar como ele está sendo assistido. Partilhar-com-os-pais suas experiências, escutá-los, acolhê-los numa verdadeira solicitude, possibilita a expressão dos seus sentimentos e a percepção pelos profissionais de saúde do que está sendo vivido, como está sendo vivido e como estão sendo afetados, adolescentes e pais, com a experiência da hospitalização. É necessário incluir a família em nossos planos de estudo, de forma que ela seja contemplada na vivência prática dos nossos alunos, de forma a despertálos para um cuidar que a acolha junto com o ser-doente.

O fenômeno desvelado aponta a necessidade de assegurar a privacidade do adolescente e de seus pais, da manutenção dos vínculos afetivos e da preparação da Unidade para recebê-los.

Entretanto, é necessário um despertar reflexivo por parte dos profissionais da enfermagem, para que esses pais também sejam vistos como seres-aí-no-mundo e como seres-no-mundo-com-o-filho-doente. A compreensão do vivido pela família, acompanhando o filho adolescente doente, aponta para uma assistência de enfermagem contemplando o binômio família e filho, tendo em vista o SER com todos os seus sentimentos, conflitos e vivência e considerando o desvelamento do fenômeno que aponta o impacto que é conviver com a internação de um filho.

5. Lima RAG, Rocha SMM, Scochi CGS. Assistência à criança hospitalizada: reflexões acerca da participação dos pais. Rev Latino-am Enfermagem 1999;7(2):33-9.

6 . Ariès P. História social da criança e da família. $2^{\underline{a}}$ ed. Rio de Janeiro (RJ): Guanabara Koogan; 1986.

7. Freitas CBP, Freitas CBD. O adolescente e a realidade brasileira. In: Maakaroun MF, Souza RP, Cruz AR, organizadores. Tratado de adolescência: um estudo multidisciplinar. Rio de Janeiro (RJ): Cultura Médica; 1991. p.9-30.

8. Saito MI. Medicina de adolescentes: Visão Histórica e perspectiva atual. In: Saito MI, Silva LEV, organizadores. Adolescência: Prevenção e Risco. São Paulo (SP): Atheneu; 2001. p. 3-9. 
9. Congresso Nacional (BR). Constituição da República Federativa do Brasil. Brasília (DF): Centro Gráfico do Senado Federal; 1988.

10. Ministério da Saúde (BR). Programa Saúde do Adolescente: bases programáticas. Brasília (DF): Ministério da Saúde; 1989.

11. Ministério da Saúde (BR). Estatuto da Criança e do Adolescente. Brasília (DF): Ministério da Saúde; 1991.

12. Ministério da Saúde (BR). Projeto Acolher. Um encontro da enfermagem com o adolescente brasileiro. Brasília (DF): Ministério da Saúde; 2000.

13. Cano MAT, Ferriani MGC, Alves AC, Nakata CY. A produção do conhecimento sobre adolescência na enfermagem: período 1983 a 1996. Rev Latino-am Enfermagem 1998 janeiro; 6(1):91-7.

14. Martins J. A ontologia de Heidegger. In: Martins J, Bicudo MAV. Estudos sobre existencialismo, fenomenologia e educação. São Paulo (SP): Moraes; 1983.

15. Heidegger M. Ser e Tempo. 9ª ed. Petrópolis (RJ): Vozes; 2000.

16. Ministério da Saúde (DF). Resolução n.196. Brasília (DF): Ministério da Saúde; 1996.

17. Heidegger $M$. Todos nós...ninguém: um enfoque fenomenológico do social. São Paulo (SP): Moraes; 1981.

18. Boemer MR. A morte, o morrer e o morrendo: estudo de pacientes terminais. [tese]. Ribeirão Preto (SP): Escola de Enfermagem/USP; 1985. 